\title{
Influence of Different Carbon Sources on Exopolysaccharide Production by Lactobacillus delbrueckii Subsp. bulgaricus (B3, G12) and Streptococcus thermophilus (W22)
}

\author{
Zehra Nur Yuksekdag* and Belma Aslim \\ Gazi University; Faculty of Science and Arts; Department of Biology; zehranur@gazi.edu.tr; Teknikokullar; Ankara \\ - Turkey
}

\begin{abstract}
Exopolysaccharides (EPSs) production was studied by Lactobacillus delbrueckii subsp. bulgaricus (B3, G12) and Streptococcus thermophilus (W22) in the medium containing various carbon sources (glucose, fructose, sucrose or lactose). For all the strains, glucose was the most efficient carbon source and B3, G12 and W22 strains produced 211, 175 and 120 EPS $\mathrm{mg} / \mathrm{L}$ respectively. Also, the influence of different concentrations of glucose $(5,10,15,20,25,30$ $\mathrm{g} / \mathrm{L})$ on EPS production and growth was studied. The results indicated that EPS production and growth were stimulated by the high glucose concentration $(30 \mathrm{~g} / \mathrm{L})$.
\end{abstract}

Key words: Lactobacillus delbrueckii subsp. bulgaricus, Streptococcus thermophilus, exopolysaccharide production, carbon sources

\section{INTRODUCTION}

Several bacteria are known to synthesize the exopolysaccharides (EPSs). EPSs occur in two forms depending on their location: as a capsule (capsular polysaccharides) where the polymer is closely associated with the cell surface and as the slime polysaccharides that are loosely associated with the cell surface. Such a distinction may be difficult since some strains release capsular polysaccharidic material at the periphery (Tallon et al., 2003). For the cells, EPSs are thought to play a role in protection against the desiccation, toxic compounds, bacteriophages, osmotic stress, and to permit the adhesion to the solid surfaces and biofilm formation (De Vuyst and Degeest, 1999). In the food industry, these polymers are used as biothickeners because of their stabilizing, emulsifying or gelling properties. The bacterial polysaccharides can also be differentiated by their chemical composition. The homopolysaccharides are composed of only one monosaccharide (glucose or fructose, mainly), and heteropolysaccharides are composed of at least two different monosaccharides. Other residues such as sn-glycerol- 3-phosphate, $N$ - acetylaminosugars, phosphate, and acetyl groups can also be found (Laws et al., 2001).

Some lactic acid bacteria (LAB) secrete a polysaccharide polymer. This exopolysaccharide (EPS) is economically important because it can impart functional effects to foods and confer beneficial health effects (Welman and Maddox, 2003). Both Lactobacillus delbrueckii subsp. bulgaricus and Streptococcus thermophilus are known to produce heteropolysaccharides (De Vuyst et al., 2003). EPS characteristics and amounts can be influenced by several factors such

*Author for correspondence 
as composition of the medium (carbon and nitrogen sources), as well as incubation conditions (temperature, $\mathrm{pH}$, time, etc.) (Looijesteijn et al., 1999; De Vuyst and Degeest, 1999; Tallon et al., 2003). That explains the diversity of the contradictory results on exopolysaccharide production. EPSs produced by lactic acid bacteria (LAB) are the subject of an increasing number of studies. LAB are food grade organisms, possessing the generally-recognized-as-safe (GRAS) status, and can produce EPSs that are potentially useful as safe additives to improve texture and viscosity of natural fermented milk products and to prevent syneresis. Moreover, it has been suggested that some EPSs produced by lactic acid bacteria may confer health benefits to the consumer (Tallon et al., 2003).

Nowadays, a lot of effort is put into the selection of new microbial strains and optimization of culture conditions to achieve higher yields of those EPSs already commercially successful. Furthermore, there is a considerable interest in finding new EPSs that are suitable for special applications, or that have potential industrial relevance, either by applying different culture conditions or by using novel bacterial strains (Looijesteijn et al., 2000). Several studies have reported that the yield of EPS produced by the lactic acid bacteria can be influenced by changing the medium composition (Van Den Berg et al., 1995; Gamar et al., 1997; Grobben et al., 1997). However, less information is available relating the effect of medium composition and concentration on the EPS production.

The purpose of this study was to determine the influence of various carbon sources (glucose, fructose, sucrose or lactose) and different concentrations of glucose $(5,10,15,20,25,30$ $\mathrm{g} / \mathrm{L}$ ) on the growth and EPS production.

\section{MATERIALS AND METHODS}

\section{Isolation, identification and growth condition}

Two strains of $L$. delbrueckii subsp. bulgaricus (G12, B3) and one strain of S. thermophilus (W22) were used in this study. L. delbrueckii subsp. bulgaricus strains were inoculated in MRS broth (Oxoid), while $S$. thermophilus strain was inoculated in M17 broth (Oxoid). All the strains were stored at $-80{ }^{\circ} \mathrm{C}$ in MRS/M17 broth with $10 \%$ glycerol, and regenerated twice before the use.
Gram stains and catalase tests were conducted to identify strains. Also, carbohydrate fermentation characteristics of all the strains were determined by using API $50 \mathrm{CHL}$ identification system. Results were recorded after $48 \mathrm{~h}$ at $42^{\circ} \mathrm{C}$. Finally, the isolates were identified by $16 \mathrm{~S}$ rDNA sequence (Tilsala-Timisjarvi and Alatossava, 1993; Ventura et al., 2000; Roy et al., 2001). The sequences obtained were searched against The Gen Bank DNA database using the blast function.

\section{Culture conditions for EPS production}

L. delbrueckii subsp. bulgaricus B3, G12 and S. thermophilus $\mathrm{W} 22$ were grown at $42{ }^{\circ} \mathrm{C}$ for $18 \mathrm{~h}$ in MRS and M17 media, respectively. Modified MRS media, containing $20 \mathrm{~g}$ of glucose (MRSglu), lactose (MRS-lac) or fructose (MRS-fru)/L, instead of the $20 \mathrm{~g}$ glucose/L normally present in MRS medium, were used to examine the EPS production by $L$. delbrueckii subsp. bulgaricus strains. Also, the modified M17 medium, containing $20 \mathrm{~g}$ of lactose (M17-lac), sucrose (M17-suc), fructose (M17-fru) or glucose (M17$\mathrm{glu} / \mathrm{L}$, instead of the $5 \mathrm{~g}$ lactose/L normally present in the M17 medium, were used to examine the EPS production by $S$. thermophilus strain. The yeast extract was taken out from the MRS and M17 media. All the media were autoclaved for 15 $\min$ at $121{ }^{\circ} \mathrm{C}$. The sugars were autoclaved separately and added to the cooled basal media.

To study the influence of the carbon source concentration on the EPS production by the strains B3, G12 and W22, glucose was added to MRS and M17 media at concentrations of 5, 10, 15, 20, 25, $30 \mathrm{~g} / \mathrm{L}$.

\section{Isolation and quantification of EPS}

After the inoculation, the cultures were incubated at $42{ }^{\circ} \mathrm{C}$ for $18 \mathrm{~h}$ and then were boiled at $100{ }^{\circ} \mathrm{C}$ for $10 \mathrm{~min}$. After cooling, they were treated with $17 \%(\mathrm{v} / \mathrm{v})$ of $85 \%$ trichloracetic acid solution and centrifuged (Frengova et al., 2000). The removal of the cells and protein was done by centrifugation. The EPS was precipitated with the ethanol $(100 \% \mathrm{v} / \mathrm{v})$. It was recovered by centrifugation at $4{ }^{\circ} \mathrm{C}$ at $14000 \mathrm{rpm}$ for $20 \mathrm{~min}$. Total EPS (expressed as $\mathrm{mg} / \mathrm{L}$ ) was estimated in each sample by the phenol-sulphuric method (Dubois et al., 1956) using glucose as the standard (Torino et al., 2001). 


\section{Statistical analysis}

The statistical analysis was performed by the SPSS (Version, 12.0). In media (MRS and M17, respectively) containing different concentrations of glucose, Person's correlation was used to determine any significant difference between the EPS production and optical density of the strains. The significance was determined at $\alpha=0.01 / 0.05$ level. If the significant differences were obtained among the treatment means $(P \leq 0.01 / 0.05)$, then the means were differentiated using the least square mean test at $\alpha \leq 0.01 / 0.05$.

\section{RESULTS AND DISCUSSION}

The influence of carbon sources (fructose, lactose or glucose for L. delbrueckii subsp. bulgaricus, sucrose, fructose, lactose or glucose for $S$. thermophilus) on the growth and production by $L$. delbrueckii subsp. bulgaricus B3, G12 strains and S. thermophilus W22 strains was studied. Using fructose, lactose and glucose the strain B3 produced 180, 203 and $211 \mathrm{mg} / \mathrm{L}$ EPS, respectively, which was by G12 produced was 69 , 113 and $175 \mathrm{mg} / \mathrm{L}$, respectively. When fructose was used as the carbon sources, the EPS production dramatically decreased. For $S$. thermophilus strain W22, with sucrose, fructose, lactose and glucose EPS 34, 40, 114 and 120 $\mathrm{mg} / \mathrm{L}$, respectively (Table 1 ).

Table 1- Influence of different carbon sources on extracellular polysaccharide (EPS) production

\begin{tabular}{lccc}
\hline Strains & Carbon Source & OD $_{\mathbf{6 0 0}}{ }^{\mathbf{a}}$ & EPS (mg/L) $\mathbf{a}^{\mathbf{a}}$ \\
\hline G12 & \multicolumn{1}{c}{ L. delbrueckii subsp. bulgaricus } & \\
& Fructose & $1.99 \pm 0.00$ & \\
& Lactose & $1.57 \pm 0.00$ & $69 \pm 4$ \\
B3 & Glucose & $1.76 \pm 0.03$ & $113 \pm 2$ \\
& & $175 \pm 0$ \\
& Fructose & $1.94 \pm 0.00$ & $180 \pm 0$ \\
& Lactose & $1.96 \pm 0.02$ & $203 \pm 0$ \\
& Glucose & $1.98 \pm 0.00$ & \\
\hline W22 & S. thermophilus & \\
& & & $34 \pm 4$ \\
& Sucrose & $2.01 \pm 0.00$ & $40 \pm 0$ \\
& Fructose & $2.04 \pm 0.04$ & $114 \pm 0$ \\
& Lactose & $2.05 \pm 0.04$ & $120 \pm 0$ \\
\hline
\end{tabular}

${ }^{\mathrm{a}}$ : Values are the means \pm standard deviations of triplicate measurements

The total yield of EPS produced by the lactic acid bacteria depends on the composition of the medium and conditions in which the organisms grow (i.e., medium, temperature and incubation time) (Cerning et al., 1990; Cerning et al., 1994). Similar observations have been made for gramnegative bacteria, including Klebsiella sp., Acinetobacter calcoaceticus (Bryan et al., 1986), and Aeromonas salmonicida (Bonnet et al., 1993). Present results showed that the yield of the EPS produced by L. delbrueckii subsp. bulgaricus and $S$. thermophilus strains depended on the carbon source and concentration present in the medium. Glucose was the most efficient carbon source for the EPS production, whereas fructose (for $L$. delbrueckii subsp. bulgaricus) and sucrose (for $S$. thermophilus) were not efficient carbon sources.

The type of carbon source has a huge influence on EPS productivity and may also affect the composition of EPS. L. delbrueckii subsp. bulgaricus NCFB 2772 produce three times more EPS with glucose than with fructose as a sugar source and the type of EPS produced by this organism was influenced by the sugar source as well (Grobben et al., 1997). Grobben et al. (1996) noted that the regulation of the EPS biosynthetic pathway in L. bulgaricus NCFB 2772 could be dependent on the carbohydrate source. Cerning et al. (1994) reported that $L$. casei CG11 was able to produce the EPS in the presence of various sugars (glucose, galactose, lactose, sucrose, maltose, 
melibiose); however, the most efficient carbon source was glucose.

When L. delbrueckii subsp. bulgaricus B3, G12, and S. thermophilus W22 were grown in media (MRS and M17, respectively) containing different concentrations of glucose $(5,10,15,20,25,30 \mathrm{~g} / \mathrm{L})$, the EPS production increased considerably (Table 2). The EPS yield obtained with $5 \mathrm{~g}$ of glucose per liter in S. thermophilus W22 was $32 \mathrm{mg} / \mathrm{L}$, while the EPS yield obtained with $30 \mathrm{~g} / \mathrm{L}$ glucose per liter in L. delbrueckii subsp. bulgaricus G12 was $255 \mathrm{mg} / \mathrm{L}$. All the three strains produced considerably more EPS when grown in the media containing glucose at high concentration $(30 \mathrm{~g} / \mathrm{L})$. Furthermore, there were significant differences in the growth (as measured by OD) (Table 2).

Table 2- Influence of different concentrations in media containing glucose on extracellular polysaccharide (EPS) production

\begin{tabular}{|c|c|c|}
\hline Concentration $(\mathrm{g} / \mathrm{l})$ & $\mathrm{OD}_{600}{ }^{\mathrm{a}}$ & EPS $(\mathrm{mg} / \mathrm{L})^{\mathrm{a}}$ \\
\hline \multicolumn{3}{|c|}{ L. delbrueckii subsp. bulgaricus $\mathrm{G} 12$} \\
\hline 5 & $0.47 \pm 0.01$ & $146 \pm 0$ \\
\hline 10 & $0.74 \pm 0.04$ & $147 \pm 1$ \\
\hline 15 & $0.94 \pm 0.06$ & $160 \pm 0$ \\
\hline 20 & $1.76 \pm 0.03$ & $175 \pm 0$ \\
\hline 25 & $2.77 \pm 0.04$ & $181 \pm 2$ \\
\hline 30 & $3.30 \pm 0.06$ & $255 \pm 3$ \\
\hline \multicolumn{3}{|c|}{ L. delbrueckii subsp. bulgaricus B3 } \\
\hline 5 & $0.59 \pm 0.00$ & $116 \pm 0$ \\
\hline 10 & $0.83 \pm 0.03$ & $137 \pm 1$ \\
\hline 15 & $1.26 \pm 0.02$ & $143 \pm 0$ \\
\hline 20 & $1.98 \pm 0.00$ & $211 \pm 1$ \\
\hline 25 & $2.19 \pm 0.02$ & $221 \pm 3$ \\
\hline 30 & $2.27 \pm 0.00$ & $224 \pm 2$ \\
\hline \multicolumn{3}{|c|}{ S. thermophilus $\mathrm{W} 22$} \\
\hline 5 & $1.08 \pm 0.04$ & $32 \pm 1$ \\
\hline 10 & $1.24 \pm 0.03$ & $55 \pm 0$ \\
\hline 15 & $1.99 \pm 0.00$ & $65 \pm 0$ \\
\hline 20 & $2.66 \pm 0.01$ & $120 \pm 0$ \\
\hline 25 & $2.99 \pm 0.00$ & $138 \pm 3$ \\
\hline 30 & $3.09 \pm 0.04$ & $174 \pm 4$ \\
\hline
\end{tabular}

a: Values are the means \pm standard deviations of triplicate measurements

There was a positive correlation $(\mathrm{r}=0.887$ for $\mathrm{G} 12$ strain, $r=0.986$ for B3 strains, $r=0.959$ for $\mathrm{W} 22$ strain) between the EPS production at highest sugar concentration in the medium and optical density and the correlation was significant at the 0.05 (for G12) or 0.01 (for B3, W22) level. It has been shown with $L$. casei (Cerning et al., 1994) and L. rhamnosus (Gamar et al., 1997) that the presence of excess sugar in the medium (at concentrations between 10 and $20 \mathrm{~g} / \mathrm{L}$ ) had a stimulating effect on EPS production, although the growth was apparently reduced. The all strains in this study did not show this effect. For B3, G12 and W22, the optimal glucose concentration for both growth and EPS production was $30 \mathrm{~g} / \mathrm{L}$.

Gamar et al. (1997) reported that EPS production and yield were influenced by the carbon source and concentration. When $L$. rhamnosus was grown in a chemically defined medium on mannose $4 \%$ w/v or glucose+fructose $2 \% \mathrm{w} / \mathrm{v}$ (ratio 1:1), the EPS production increased by three or four times whereas the final biomass concentrations were identical.

In conclusion, L. delbrueckii subsp. bulgaricus B3, G12 and $S$. thermophilus W22 were able to produce the EPS in the presence of various sugars; however, the most efficient carbon source was glucose. Furthermore, the sugar concentration had a marked effect on the EPS production. For instance, raising the glucose concentration resulted in increased EPS production.

\section{ACKNOWLEDGEMENTS}

This study was supported by the TUBITAK project no TBAG-2090 101T129. 


\section{REFERENCES}

Bonnet, R.; Simon-Pujol, M. D. and Congregado, F. (1993), Effects of nutrients on exoploysaccharide production and surface properties of Aeromonas salmonicida. Appl. Environ. Microbiol., 59, 24372441.

Bryan, B. A., Linhardt, R. J. and Daniels, L. (1986), Variation in composition and yield of exopolysaccharides produced by Klebsiella sp. Strain K32 and Acinetobacter calcoaceticus BD4. Appl. Environ. Microbiol., 51, 1304-1308.

Cerning, J.; Boullanne, C.; Landon, M. and Desmazeaud, M. J. (1990), Comparison of exocellular polysaccharide production by thermophilic lactic acid bacteria. Science Aliments, 10, 443-451.

Cerning, J.; Renard, C. M. G. C.; Thibault, J. F.; Boullanne, C.; Landon, M.; Desmazeaud, M. and Topisirovic, L. (1994), Carbon source requirements for exopolysaccharide production by Lactobacillus casei CG11 and partial structure analysis of the polymer. Appl. Environ. Microbiol., 60, 3914-3919.

De Vuyst, L. and Degeest, B. (1999), Heteropolysaccharides from lactic acid bacteria. FEMS Microbiol. Rev., 23, 153-177.

De Vuyst, L.; Zamfir, M.; Mozzi, F.; Adriany, T.; Marshall, V.; Degeest, B. and Vaningelgem, F. (2003), Exopolysaccharide-producing Streptococcus thermophilus strains as functional starter cultures in the production of fermented milks. Int. Dairy J., 13, 707-717.

Dubois, M.; Gilles, K. A.; Hamilton, J. K.; Peters, P. A. and Smith, F. (1956), Colorimetric method for determination of sugars and related substances. Analytical Chem., 28, 350-356.

Frengova, G. I.; Simova, E. D.; Beshkova, D. M. and Simov, Z. I. (2000), Production and monomer composition of exopolysaccharides by yogurt starter cultures. Canadian J. Microbiol., 46, 1123-1127.

Gamar, L.; Blondeau, K. and Simonet, J. M. (1997), Physiological approach to extracellular polysaccharide production by Lactobacillus rhamnosus strain C83. J. Appl. Microbiol., 83, 281287.

Grobben, G. J.; Smith, M. R.; Sikkema, J. and de Bont, J. A. M. (1996), Influence of fructose and glucose on the production of exopolysaccharides and the activities of enzymes involved in the sugar metabolism and the synthesis of sugar nucleotides in Lactobacillus delbrueckii subsp. bulgaricus NCFB 2772, Appl. Microbiol. Biotechnol., 46, 279-284.

Grobben, G. J.; Van Casteren, W. H. M.; Schls, H. A.; Oosterveld, A.; Sala, G.; Smith, M. R.; Sikkema, J. and Bont, J. A. M. (1997), Analysis of the exopolysaccharides produced by Lactobacillus delbrueckii subsp. bulgaricus NCFB 2772. Appl. Microbiol. Biotechnol., 48, 516-521.

Laws, Y.; Gu, Y. and Marshall, V. (2001), Biosynthesis, characterisation, and design of bacterial exopolysaccharides from lactic acid bacteria. Biotechnol. Advences, 19, 597-625.

Looijesteijn, P. J.; Boels, I. C.; Kleerebezem, M. and Hugenholtz, J. (1999), Regulation of exopolysaccharide production by Lactobacillus lactis subsp. cremoris by the sugar source. Appl. Environ. Microbiol., 65, 5003-5008.

Looijesteijn, P. J.; van Casteren, W. H. M.; Tuinier, R.; Doeswijk-Voragen, C. H. L. and Hugenholtz, J. (2000), Influence of different substrate limitations on the yield, composition and molecular mass of exopolysaccharides produced by Lactococcus lactis subsp. cremoris in continuous cultures. J. Appl. Microbiol., 89, 116-122.

Roy, D.; Sirois, S. and Vincent, D. (2001), Molecular discrimination of Lactobacilli used as starter and probiotic cultures by amplified ribosomal DNA restriction analysis. Curr. Microbiol., 42, 282-289.

Ruas-Madiedo, P.; Tuinier, R.; Kanning, M. and Zoon, P. (2002), Role of exopolysaccharide by Lactococcus lactis subsp. cremoris on the viscosity of fermented milks. Int. Dairy J., 12, 689-695.

Tallon, R.; Bressollier, P. and Urdac1, M. C. (2003), Isolation and characterization of two exopolysaccharides produced by Lactobacillus plantarum EP 56. Research Microbiol., 154, 705-712.

Tilsala-Timisjarvi, A. and Alatossava, T. (1993), Enzymatic amplification of 16s rRNA gene sequences from dairy Lactobacillus species. Milchwissenschaft, 48, 123-125.

Torino, M. I.; Taranto, M. P.; Sesma, F. and Font de Valdez, G. (2001), Heterofermentative pattern and exopolysaccharide production by Lactobacillus helveticus 15807 in response to environmental $\mathrm{pH}$. $J$. Appl. Microbiol., 91, 846-852.

Van Den Berg, D. J. C.; Robijn, G. W. and Janssen, A. C. (1995), Production of a novel extracellular polysaccharide by Lactobacillus sake 0-1 and charecterization of the polysaccharide. Appl. Environ. Microbiol., 61, 2840-2844.

Ventura, M.; Casas, I. A.; Morelli, L. and Callegari, M. (2000), Rapid amplified ribosomal DNA restriction analysis (ARDRA) identification of Lactobacillus spp. isolated from fecal and vaginal samples. Sys. Appl. Microbiol., 23, 504-509.

Welman, A. D. and Maddox, I. S. (2003), Exopolysaccharides from lactic acid bacteria: perspectives and challenges. TRENDS Biotechnol., 21, 269-274.

Received: January 25, 2007; Revised: June 11, 2007; Accepted: January 14, 2008. 
PÁGINA

EM

BRANCO 